\title{
FIGUR PEREMPUAN JAWA DALAM DAMAR KURUNG SEBAGAI INSPIRASI PENCIPTAAN MOTIF BATIK KHAS GRESIK
}

\author{
Javanese Women Figure in damar kurung as An Inspiration for Batik Motif of Gresik \\ Characteristic
}

Aniendya Christianna dan Luri Renaningtyas

Fakultas Seni dan Desain, Universitas Kristen Petra, Surabaya, Indonesia

\begin{tabular}{ll}
\hline Korenspondensi Penulis & Naskah Masuk : 20 April 2020 \\
Email $:$ aniendya@petra.ac.id & Revisi 29 Juni 2020 \\
& Disetujui $: 10$ Juli 2020 \\
\hline
\end{tabular}

Kata kunci: batik, damar kurung, perempuan, budaya, jawa

Keywords: batik, damar kurung, woman, culture, java

\begin{abstract}
ABSTRAK
Penciptaan seni motif batik ini merupakan penelitian kualitatif dengan metode deskriptif yang digunakan untuk mendeskripsikan performa perempuan Jawa dalam ragam hias damar kurung. Proses penciptaan seni ini dilaksanakan selama kurang lebih 8 bulan yang meliputi tahap penelitian, tahap perancangan dan tahap implementasi hasil perancangan. Metode analisis data yang digunakan adalah deskriptif, yang berguna untuk menguraikan temuan faktual karakteristik ragam hias damar kurung beserta dengan kronologi sejarahnya. Temuan data diklasifikasikan sesuai dengan temuan tema performativitas perempuan, untuk kemudian dikembangkan sebagai inovasi motif batik khas Gresik. Tujuan dari penelitian ini adalah pengembangan ragam hias damar kurung menjadi motif batik, serta sebagai salah satuupaya konservasi melestarikan damar kurung sebagai warisan tak benda Nasional. Serta untuk mengetahui identitas maupun peran gender perempuan dalam kebudayaan Jawa. Luaran penelitian ini berupa seni motif batik dengan nama: motif batik ubet, motif batik srawung dan motif batik rame ing gawe, diharapkan dapat berkontribusi bagi para desainer dan praktisi seni dan atau kriya agar dapat memanfaatkan warisan budaya lokal untuk meningkatkan ekonomi industri kreatif.
\end{abstract}

\section{ABSTRACT}

The creation of this batik motif art is a qualitative research using descriptive methods used to describe the performance of Javanese women in the damar kurung decorative style. The process was carried out for approximately 8 months which included the research phase, the design phase, and the implementation phase. The data analysis method used is descriptive, which is useful for describing the factual findings of the characteristics of the damar kurung decoration. The data findings are classified according to the findings of the female performance themes and then developed as an innovation in the typical Gresik batik motif. The purpose of this research is the development of damar kurung decoration into batik motifs as conservation efforts to preserve damar kurung as a national intangible heritage. And to find out the identity and role of women's gender in Javanese culture. The outputs of this research are in the form of batik motifs with the names: ubet batik motifs, srawung batik motifs and rame ing gawe batik motifs, which are expected to contribute to the designers and practitioners of the art and/or crafts so that they can utilize the local cultural heritage to improve the economy of the creative industries. 


\section{PENDAHULUAN}

Sejak UNESCO menetapkan batik sebagai warisan kemanusiaan untuk budaya lisan dan non-bendawi (masterpiece of the oral and intangible heritage of humanity) pada bulan Oktober tahun 2009 (Hakim, 2018) banyak daerah di Indonesia berupaya mengeksplorasi keunikannya sebagai inspirasi motif batik khas daerahnya. Demikian pula dengan Gresik, salah satu kawasan pesisir utara dan pusat industri di Provinsi Jawa Timur (BPS Gresik Regency, 2013). Kondisi sosial-ekonomi masyarakat yang didominasi perindustrian, secara perlahan telah mengikis ciri khas budaya khas Gresik. Termasuk dalam upaya menggali motif batik khas Gresik.

Ikan bandeng seringkali menjadi inspirasi motif batik, karena Gresik memang memiliki tradisi warisan sejak masa Sunan Giri yang tetap lestari hingga saat ini, yaitu tradisi pasar bandeng (Uyun, 2017). Tradisi pasar bandeng diadakan setiap dua hari menjelang bulan Ramadhan sebagai wujud keterkaitan ibadah agama dengan kehidupan ekonomi masyarakat.

Selain ikan bandeng, sebenarnya Gresik juga memiliki tradisi khas yang juga dapat menjadi sumber inspirasi motif batik khas Gresik, yakni damar kurung karya Masmundari (Syabrina, 2014) seperti yang terlihat dalam Gambar 1.

damar kurung merupakan lentera khas Gresik yang kini mulai langka (Utama, 2015). damar kurung pada mulanya merupakan sebuah lentera yang dinyalakan sepanjang bulan puasa untuk menyambut datangnya Hari Raya Idul Fitri (Christianna, 2018a).

Lentera ini digunakan sebagai penerang sekaligus penanda bagi masyarakat untuk melaksanakan sholat tarawih berjamaah. Terdapat ragam hias yang khas pada kertas pembungkus damar kurung (Ismoerdjahwati, 2014). Ragam hias yang menggambarkan situasi sosialekonomi-kultur masyarakat Gresik dan digambarkan secara unik, dekoratif dan naif. Tradisi ini bertahan sejak abad ke-16, tetapi ketika teknologi lampu listrik mendominasi kehidupan masyarakat, fungsi damar kurung perlahan tergeser (Wahyu, 2013).

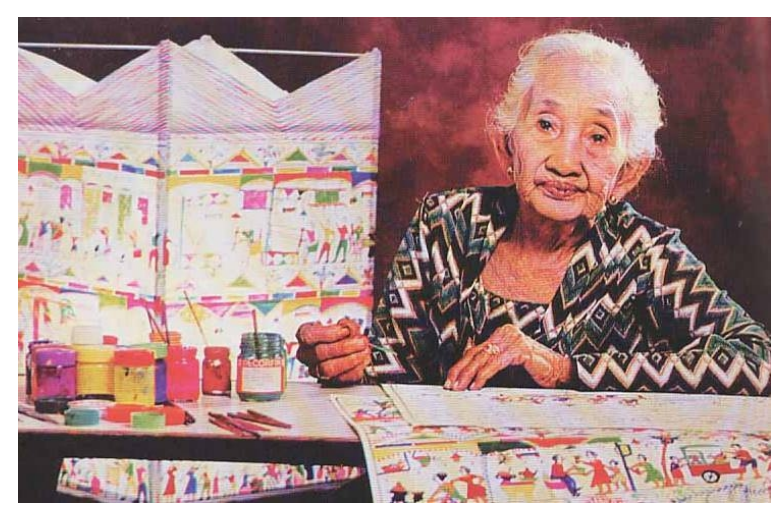

Gambar 1. damar kurung (Indrakusuma, 2003)

Ragam hias damar kurung telah merekam peradaban masyarakat Gresik sejak abad ke-16. Menjelang kepunahannya, tersiar kabar baik dari Kementerian Pendidikan dan Kebudayaan Republik Indonesia yang telah menetapkan damar kurung Gresik sebagai warisan budaya tak benda nasional pada 4 Oktober 2017 (Christianna, 2020). Hal ini menjadi angin segar bagi upaya berbagai pihak untuk melestarikan damar kurung agar eksistensinya bisa diapresiasi oleh masyarakat luas, terutama generasi muda.

Masmundari sebagai perempuan (1904-2005, usia 101 tahun) melukiskan identitas perempuan Jawa melalui ragam hias damar kurung karyanya. Identitas adalah sesuatu yang tidak dapat dipisahkan 
dari diri manusia (Trismaya, 2018). Karena manusia hidup dalam dimensi sosial yang memaksanya untuk terus menerus menghadapi dan merumuskan identitas yang menandakan keberadaannya. Konteks budaya dimana perempuan lahir, tinggal dan dibesarkan memberi andil yang besar dalam perempuan membangun identitas dirinya dalam masyarakat (Rohman, 2018). Demikian pula dengan Masmundari. Kebudayaan Jawa mempunyai caranya sendiri yang khas dalam membangun identitas perempuan.

Berdasarkan paparan tersebut, maka dapat dirumuskan bahwa ragam hias damar kurung dapat menjadi inspirasi alternatif motif batik khas Gresik. Dengan demikian, ragam hias masa lalu dapat kembali dikenal dan diapresiasi oleh masyarakat dengan menyesuaikan kebutuhan masa kini. Serta dapat menambah khasanah ragam hias dan pola batik nusantara. Hal ini mendorong pengembangan desain yang berbasis kearifan lokal untuk mendukung peningkatan ekonomi industri kreatif. Serta dapat mewujudkan usaha konservatif budaya yang mencakup keseluruhan teknik, teknologi dan pengembangan motif dan budaya yang melatarbelakangi. Bukankah memproduksi batik berarti merayakan kreatifitas baik dari segi teknik, teknologi, estetik maupun budayanya.

\section{Pola Hias Batik Pesisir}

Pola hias batik terdiri atas dua komponen utama, yaitu ornamen motif dan isen-isen motif batik (Sachari, 2010). Ornamen motif batik terbagi menjadi dua yaitu ornamen utama dan ornamen pendukung. Ornamen utama yang menentukan pola hias secara keseluruhan dan biasanya memiliki makna tertentu. Sedangkan ornamen pendukung/tambahan berfungsi sebagai pendukung ornamen utama. Isen-isen merupakan hiasan yang diterapkan dalam batik untuk menambah keindahan, biasanya berupa bentuk geometris yang sederhana dan berukuran kecil, seperti rangkaian titik, garis lurus, garis putus-putus, atau bentuk lainnya yang lebih (Rasjoyo, 2008).

Pola hias batik digolongkan menjadi dua berdasarkan komposisinya, yaitu pola hias geometrik, non geometrik dan pinggiran. Pola hias geometrik terdiri dari susunan ornamen yang mengacu pada bentuk geometris, seperti lingkaran, persegi, segitiga, dan jajaran genjang. Pola hias geometrik terbagi menjadi beberapa teknik yaitu: tubrukan, onde-ende, parang, dan mubeng (Christianna et al., 2020) seperti yang ditunjukkan pada Gambar 2.

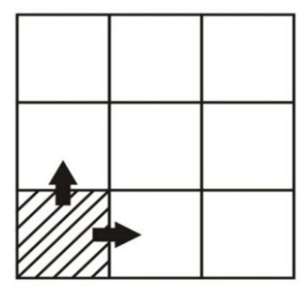

(a)

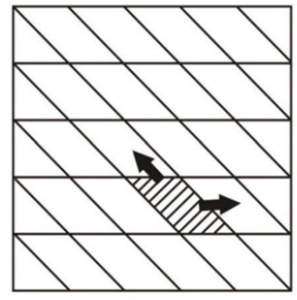

(c)

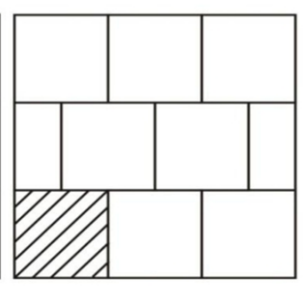

(b)

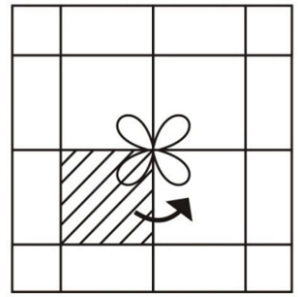

(d)
Gambar 2. (a) Tubrukan; (b) Onde-onde; (c) Parang, dan (d) mubeng (Tjahjani, 2013)

Pola hias geometrik tubrukan dan onde-onde menggunakan bentuk persegi sebagai acuan. Ornamen-ornamen batik diulang sejajar ke kanan atau ke atas. Lain 
halnya dengan pola hias geometrik parang, ornamen diulang sejajar kekanan atau keatas, tetapi menggunakan bentuk jajaran genjang sebagai acuan.

Pola hias geometrik mubeng menerapkan pengulangan ornamen yang melawan arah jarum jam.

Sedangkan, pola hias non-geometrik disusun secara bebas meski terdapat pengulangan. Batik kontemporer saat ini telah banyak menerapkan pola hias nongeometrik dengan pertimbangan estetika dan permintaan pasar yang semakin beragam. Pinggiran batik adalah pola hias yang khusus digunakan sebagai hiasan pinggiran kain atau sebagai pembatas antara ornamen satu dengan ornamen yang lain.

Daerah pesisir Pulau Jawa identik dengan kondisi sosial-kultur yang multi etnis. Masyarakat pesisir cenderung memiliki sifat yang terbuka dalam menerima pengaruh dari luar wilayahnya. Serta memiliki kepekaan dalam menangkap perubahan sosial yang terjadi. Sikap terbuka inilah yang mendorong terjadinya akulturasi budaya, yang kemudian turut mendorong kreativitas penciptaan karya seni baru. Kreativitas perajin terus bergeliat seiring dengan perkembangan zaman dan kebutuhan pasar. Ciri khas batik pesisir terletak pada ornamennya yang bersifat naturalis, menggambarkan pengaruh kebudayaan asing dan memiliki corak serta warna yang lebih beragam akibat pengaruh kebudayaan Tiongkok dan kolonial (Wulandari, 2011).

\section{Warisan Batik di Gresik}

Sampai akhirnya pada Bulan Januari tahun 2017, Batik Pamiluto Ceplokan
(Gambar 3) dipatenkan oleh Kementerian Hukum dan HAM (Kemenkumham) RI sebagai batik khas Gresik (Agustina, 2017). Munculnya motif batik ini diawali dengan sayembara yang diadakan oleh Dewan Kerajinan Nasional Daerah, diikuti lebih dari 1.000 orang peserta, mulai pelajar sampai masyarakat umum. Gapura makam Maulana Malik Ibrahim, makam Sunan Giri, pudak (kuliner khas Gresik), rusa pulau Bawean dan ikan bandeng menjadi inspirasi motif batiknya. Ada pula motif batik lain yang juga dikenal sebagai motif batik khas Gresik meski belum dipatenkan, yaitu batik loh bandeng dan batik ndulit sisik bandeng (Agustina, 2017).

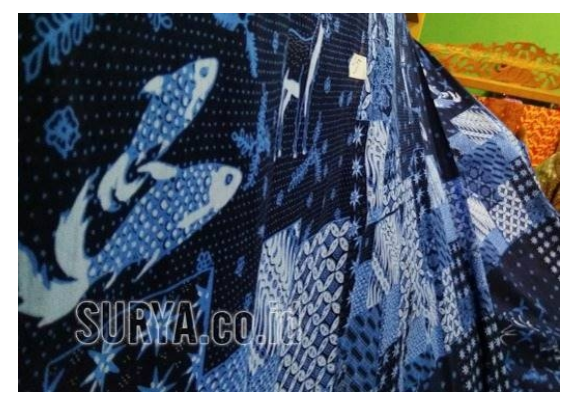

Gambar 3. Batik Pamiluto Ceplokan Gresik ("Loh Bandeng Salah Satu Ikon Batik Gresik," 2012)

\section{Konsep Perempuan Jawa}

Prinsip yang dipegang teguh manusia Jawa ada pada kebatinannya. Dalam filosofi Jawa, alam kebatinan merupakan realitas yg paling dalam. Keyakinan manusia Jawa yaitu menekankan prinsip harmoni, keselarasan dan keseimbangan dalam hubungan antara makrokosmos dan mikrokosmos (Pratiwinindya, 2017).

Karakter perempuan Jawa tidak dapat dilepaskan dari budaya Jawa, sebagaimana digambarkan sebagai pribadi yang halus, tenang, kalem, menghindari konflik, mengutamakan harmoni, mengutamakan keluarga serta memiliki pengendalian diri 
ClKh Dinamika Kerajinan dan Batik: Majalah Ilmiah. Vol. 38 No. 1, Juni 2021, hal. 13 - 28

yang tinggi (Pramudita, 2016). Y.B Mangunwijaya dalam Genduk Duku (Sastriyani, Hariti, dan Kayam, 1997) menganggap sedemikian penting peranan perempuan hingga kejayaan seorang lakilaki/suami tergantung pada bagaimana ia bersedia diperbaiki perilakunya oleh perempuan/istri. Seperti yang dijelaskan oleh Jati (Pramitasari, 2017) tentang konsep ardhananeswari untuk memahami status perempuan Jawa. Lebih lanjut, tubuh dan status perempuan adalah sumber kehidupan manusia, termasuk laki-laki. Hal itu yang kemudian membuat posisi laki-laki secara langsung maupun tak langsung bergantung pada kehadiran perempuan. Posisi perempuan disebut sebagai prameswari yakni pengendali sekaligus penasehat bagi pria dalam menjalankan fungsi kepemimpinannya (Pramitasari, 2017). Perempuan Jawa mampu membuktikan bahwa dirinya mampu sejajar dengan lakilaki dalam menunaikan perannya. Meski demikian, perempuan Jawa dengan kejawaannya dituntut untuk selalu menjunjung tinggi nilai-nilai kearifan Jawa.

\section{Masmundari: Seniman Perempuan \\ Pelukis damar kurung}

Sriwati Masmundari atau Nyimas Mundari lahir di Desa Kroman kabupaten Gresik, Jawa Timur pada 4 Januari 1904 (Christianna, 2018b). Pada tahun 1980an Masmundari tercatat sebagai satu-satunya pembuat dan pelestari kerajinan damar kurung khas Kota Gresik. Menurut wawancara dengan kolektor damar kurung. Muzachim (66 tahun), damar kurung tertua yang ditemukan adalah karya Kyai Untung yang dimensinya lebih besar daripada karya
Masmundari. Ragam hiasnya cenderung mirip dengan ilustrasi pewayangan.

damar kurung dibuat untuk dijual satu kali dalam setahun yaitu untuk menyambut datangnya Bulan Ramadhan sebagai lampu penerang sekaligus penghias teras rumah. Ragam hias yang menghiasi permukaan damar kurung menjadi media pitutur/mendongeng oleh orang tua kepada anak-anaknya. Karena ragam hias damar kurung menggambarkan situasi sosial-budaya masyarakat Gresik yang dinamis. Namun, lambat laun tradisi tersebut semakin hilang karena mulai banyaknya teknologi penerangan yang lebih modern. Perajinnya pun berangsur beralih profesi, tanpa meninggalkan warisan pelestarian kepada generasi selanjutnya. Tersisa Masmundari yang sampai hayatnya konsisten melestarikan damar kurung.

Ragam hias damar kurung yang dilukis Masmundari dikategorikan sebagai lukisan bergaya naivisme oleh banyak pengamat seni (Indrakusuma, 2003). Benedetti, Joan M (Benedetti, 2008) mendefinisikan naivisme sebagai aliran seni yang mengutamakan elemen dan kualitas visual yang melawan aturan baku pendidikan seni konvensional. Ciri khas ini tampak pada teknik drawing yang tidak proporsional, tidak menguasai konsep perspektif, sederhana dan memiliki warna cerah. Gaya lukis Masmundari ini lekat dengan pengaruh buku Babad Sindujoyo (Ismoerdjahwati, 2014), seperti terlihat pada Gambar 4.

Babad Sindujoyo merupakan naskah kuno yang dibuat pada tahun 1850 yang berkisah tentang riwayat hidup Kyai Sindujoyo santri dari Sunan Prapen, tokoh yang dikenal sebagai pembuka kawasan 
Kroman dan Lumpur di Gresik (Udin, 2015). Naskah kuno yang ditulis oleh Ki Tarub
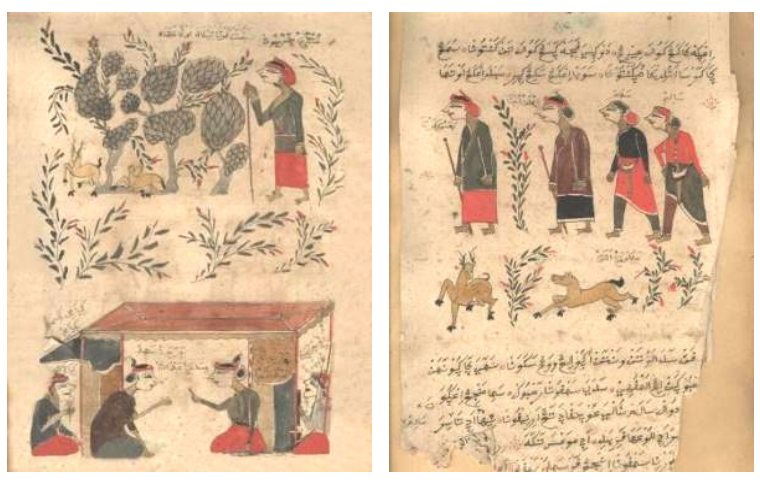

Gambar 4. Babad Sindujoyo

(Sumber: Dokumentasi pribadi dari koleksi Oemar Zainuddin)

Agung ini berupa buku tebal dengan sampul kulit setebal $5 \mathrm{~cm}$ dengan isi kurang lebih 200 halaman (Utama, 2017). Buku ini sangat menarik karena ditulis dengan huruf Arab dengan bahasa Jawa/Arab Pegon disertai dengan ilustrasi berwarna (Mashuri, 2017). Ilustrasi dalam Babad Sindujoyo dan ragam hias damar kurung karya Masmundari menunjukkan adanya kemiripan, yakni menggambarkan sosok manusia dengan teknik stilasi yang sederhana dan tampak menyamping. Teknik menggambar seperti ini, seringkali didapati pada karakter penggambaran wayang kulit dan relief candi. Keterkaitan keduanya membuktikan bahwa kesenian damar kurung telah ada sejak lama merekam peradaban masyarakat Gresik yang dinamis.

\section{METODOLOGI PENELITIAN}

\section{Metode Pengumpulan Data}

Penciptaan seni ini merupakan penelitian kualitatif dengan metode deskriptif yang digunakan untuk mendeskripsikan ragam hias damar kurung. Penelitian ini dilaksanakan selama kurang lebih delapan bulan yang meliputi tahap penelitian, tahap perancangan dan tahap implementasi hasil perancangan, sebagai berikut:

a. Tahap Pengumpulan Data, meliputi:

- Studi literatur

- Tinjauan ragam hias damar kurung

- Klasifikasi ragam hias damar kurung berdasarkan tema

- Tinjauan ragam hias batik khas Gresik

b. Tahap Perancangan Desain, meliputi:

- Eksplorasi ragam hias batik berdasarkan temuan tema ragam hias damar kurung

- Sketsa desain pola batik, motif dan ragam hias batik

- Analisis desain dan tinjauan estetika

- Pengembangan dan revisi desain

c. Tahap Implementasi Hasil Perancangan, meliputi:

- Pengembangan dan revisi desain

- Memilih desain terbaik

- Purwarupa

Metode pengumpulan data ditempuh melalui:

a. Studi literatur untuk menemukan data dan informasi yang berkaitan dengan sejarah dan ragam hias damar kurung.

b. Wawancara dengan perajin batik di Gresik dan para kolektor damar kurung.

c. Dokumentasi dan observasi lapangan untuk memperoleh data yang faktual tentang ragam hias damar kurung. Data lapangan diperoleh dari observasi ke UKM batik di Gresik.

\section{Metode Analisis Data}

Metode analisis data yang digunakan adalah deskriptif, yang berguna untuk 
menguraikan temuan faktual karakteristik ragam hias damar kurung beserta dengan kronologi sejarahnya. Temuan data diklasifikasikan sesuai dengan temuan tema, untuk kemudian dikembangkan sebagai inovasi motif batik yang baru. Tahap selanjutnya adalah merancang sketsa alternatif desain mulai dari corak utama, corak pendukung, isen-isen, latar dan pinggiran. Kemudian rancangan alternatif desain itu dianalisis dari berbagai sudut pandang estetika. Hasil analisis tersebut selanjutnya dikembangkan hingga ditentukan desain yang terbaik sebagai motif batik. Desain terbaik akan diimplementasikan dalam purwarupa.

\section{HASIL DAN PEMBAHASAN}

Perempuan Jawa dalam Ragam Hias

\section{damar kurung}

Membahas tentang Jawa sama dengan membahas tentang masyarakat yang telah berbenturan dan terbentuk dari berbagai kebudayaan dan peradaban lain selama puluhan dasawarsa silam. Hal itu tampak pada kompleksitasnya yang sangat besar, baik dalam tataran sistem pemikiran maupun perilakunya. Kompleksitas tersebut merupakan hasil dari proses sosio-histori yang panjang, dan kadang tidak sepenuhnya disadari sebagai struktur pondasi mental oleh manusia Jawa sendiri.

Geertz (Geertz, 1990) menjelaskan bahwa menurut dasar epistemologi kebudayaan Jawa, hidup manusia mengacu pada dua hal: lahir dan batin. Kehidupan lahiriah manusia Jawa berkaitan dengan seluruh perilaku yang melibatkan indera, seperti makan, minum, bekerja, berkendara, berbelanja, rekreasi dan sebagainya. Hidup batiniah mencakup 'tempat' dan perilaku yang paling pribadi dari manusia Jawa. Di 'tempat' itulah manusia Jawa 'mengambil jarak dan menyendiri' dari berbagai ritual harian yang bersifat lahiriah. Gagasan hidup lahiriah disebut sebagai realitas material, maka hidup batiniah disebut sebagai realitas spiritual. Filosofi hidup Jawa tidak memisahkan aspek lahir dan batin, justru keduanya berkelindan saling melengkapi membentuk harmonisasi.

Konsep identitas manusia Jawa dibangun secara komprehensif karena meliputi aspek moral, agama, psikologis, sosial-budaya dan ekonomi yang kesemuanya terjalin membangun identitas manusia Jawa. Paduan berbagai aspek tersebut tidak dapat dilepaskan dari filosofi hidup budaya Jawa yang berorientasi pada keseimbangan aspek lahir dan batin. Demikian pula dengan relasi gender antara laki-laki dan perempuan yang saling menjaga harmonisasi lahir dan batin kosmos Jawa.

Sebagai seorang seniman perempuan, Masmundari justru memberi ciri yang khas pada ragam hias damar kurung. Sebagian besar hasil karyanya merupakan hasil pengamatan perkembangan sosial-budaya masyarakat Gresik yang digambar secara spontan (tanpa menggunakan sketsa awal). Posisi dan peran perempuan juga tak luput dari pengamatan Masmundari. Mengamati lukisan ragam hias damar kurung buatan Masmundari merupakan upaya untuk membangun identitas sekaligus mengidentifikasi performativitas perempuan Jawa. Adapun temuan tema ragam hias damar kurung yang mengidentifikasi peran perempuan ada dalam hal: (1) perempuan dalam kegiatan ekonomi, (2) perempuan dan teknologi, dan (3) perempuan dalam 
upacara tradisional. Ada pun ketiga hal tersebut dijelaskan lebih lanjut sebagai berikut.

\section{(1) Perempuan dalam kegiatan ekonomi}

Ragam hias damar kurung karya Masmundari menggambarkan berbagai variasi aktifitas yang dilakukan perempuan, salah satunya adalah kegiatan ekonomi, baik sebagai posisi penjual maupun pembeli (Gambar 5).

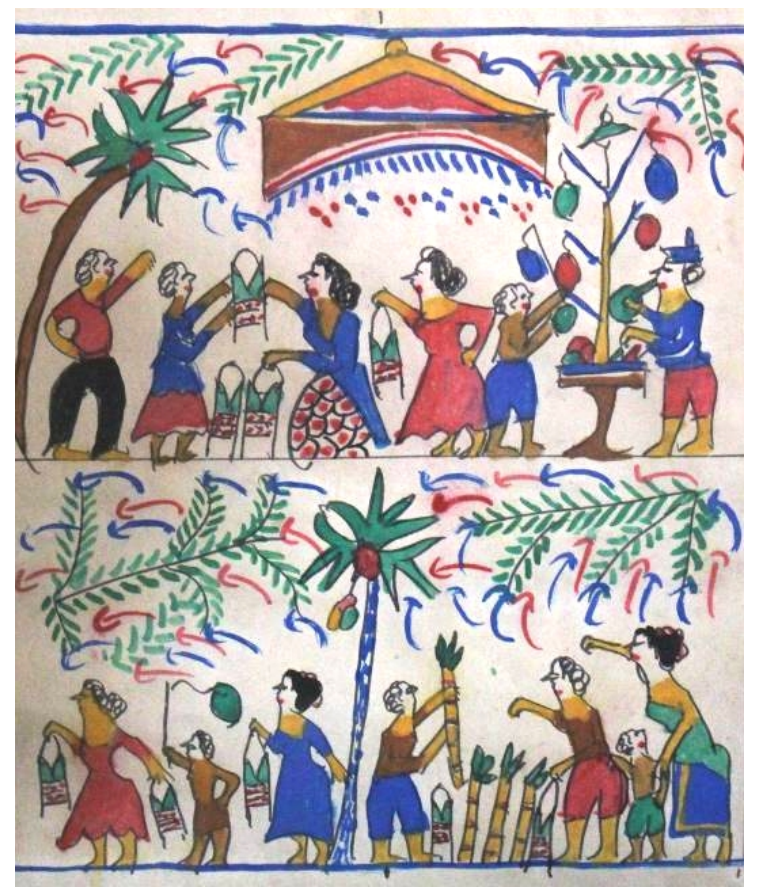

Gambar 5. Ragam Hias damar kurung dengan tema Perempuan dan Kegiatan Ekonomi (Dokumentasi peneliti dari koleksi Oemar Zainuddin)

Komoditas yang tampak adalah lentera, tuak (minuman khas Gresik), ikan bandeng, makanan, buah, dan pakaian, dengan latar belakang suasana pasar.

Dalam filosofi Jawa terdapat ungkapan sepi ing pamrih rame ing gawe (berarti: tidak mengedepankan ego, melakukan pekerjaan sepenuhnya) yang berlaku tidak hanya untuk laki-laki, namun perempuan pun mengacu pada panduan hidup itu.

Tidak ada ukuran pasti bahwa perempuan harus bekerja dengan jabatan tertentu, memiliki kompetensi tertentu, bekerja pada waktu yang ditentukan dan menghasilkan pendapatan minimal, perempuan Jawa secara sadar dan sukarela mengusahakan segala sesuatu untuk menjaga stabilitas rumah tangganya.

Rumah tangga selalu dianggap sebagai tiang pusat dunia perempuan Jawa, sementara pekerjaan adalah salah satu bentuk perluasan ruang gerak rumah tangga. Jodelet (Permanadeli, 2015) menyebutkan bahwa rumah tangga menjadi pusat yang menentukan struktur pandangan atas dunia sosial. Umumnya aktivitas ekonomi yang dilakukan perempuan Jawa bersifat informal dan tidak diakui sebagai struktur ekonomi sistem produksi, misalnya aktivitas di pasar seperti yang ditunjukkan pada Gambar 6.

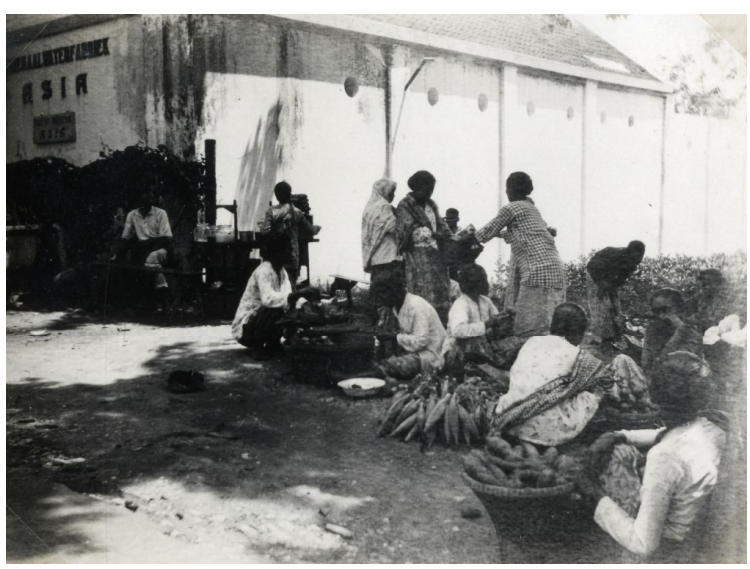

Gambar 6. Suasana pasar di Gresik

(Sumber: Arsip Universitas Leiden)

Pusat dari aktivitas ekonomi informal adalah ekonomi rumah tangga, oleh karena itu Masmundari melukis aktivitas menjual makanan, ikan bandeng, buah, pakaian dan membuat batik, yang merupakan 
perpanjangan dari aktivitas rumah tangga itu sendiri. Dan patut dicatat bahwa kini ekonomi Indonesia telah berevolusi dan berkembang menjadi ekonomi berbasis industri kreatif berkat aktivitas ekonomi informal ini.

Makna simbolik tentang perempuan Jawa yang bekerja adalah representasi dari kemampuan tiap manusia Jawa untuk menghormati dan menjaga keseimbangan tatanan kosmos budaya Jawa. Perempuan bekerja dalam ruang sosial bukanlah demi kepentingan privat semata. Perempuan yang secara sadar, sukarela dan mandiri dapat mengusahakan potensi ekonominya merupakan suatu perwujudan kedewasaan mental perempuan sekaligus menunjukkan tanda dari kemampuannya untuk memberdayakan diri dan orang. Melalui dunia kerja perempuan dapat membangun jejaring sosial (dalam konsep filosofi Jawa disebut srawung) yang memperluas wawasan sekaligus relasi sosial. Dengan demikian, bagi perempuan Jawa bekerja dan rumah tangga bukanlah dua dunia yang saling berlawanan. Perempuan bertanggung jawab penuh terhadap sumber daya ekonomi rumah tangga sekaligus sumber daya masyarakat.

\section{(2) Perempuan dan Teknologi}

Dalam filosofi Jawa dikenal istilah ubet, berarti gagasan kerja yang dilakukan oleh perempuan, sedangkan sebagai kata sifat ubet bermakna ulet bekerja dan terus bergerak (Soedarsono SP, 1998). Poensen (Risa Permanadeli, 2015) menyebutkan "Perempuan bertugas memelihara padi yang sudah mereka tanam, mereka juga yang memanen, mengeringkan dan kemudian menumbuknya. Perempuan pula yang memasak nasi dan membuat bumbu... Mereka membeli peralatan rumah tangga... Mereka membeli gerabah... Mereka membatik dan menjual batik yang sudah jadi".

Dalam prakteknya, ubet menunjukkan pada gagasan selalu bergerak, aktif dan ulet untuk menghasilkan pendapatan. Perempuan Jawa disebut ubet jika aktif keluar rumah untuk srawung (bersosialisasi) dan menghasilkan pendapatan yang dapat menyokong keberlangsungan rumah tangganya. Perempuan yang aktif direpresentasikan dengan penguasaan terhadap teknologi, baik teknologi komunikasi maupun transportasi, yang memungkinkan perempuan memperluas jangkauan sosialisasinya. Masmundari mengartikulasikannya dalam gambar perempuan yang mengendarai sepeda, naik delman atau pesawat terbang.

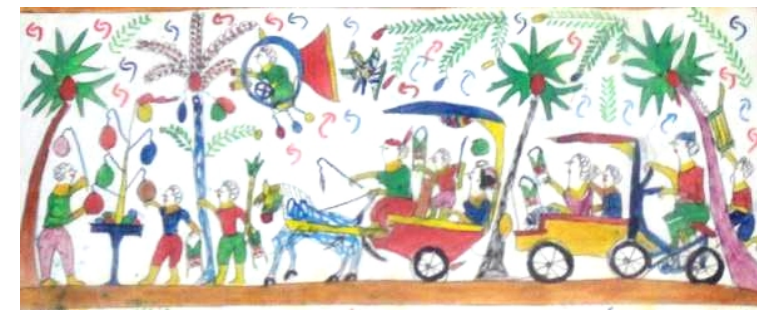

Gambar 7. Ragam Hias damar kurung dengan tema Perempuan dan Teknologi-Pesawat (Dokumentasi peneliti dari koleksi Oemar Zainuddin)

Dalam konteks produksi ragam hias damar kurung oleh Masmundari pada tahun 80an sampai dengan 90an, Gresik mengalami kemajuan yang sangat pesat karena industrialisasi (Gambar 7). Investor gencar menanamkan modalnya di Gresik dan berdampak pada peralihan mata pencaharian sebagian besar warga Gresik. Sebagian besar nelayan dan tani bergeser 
menjadi buruh pabrik. Terjadinya modernisasi besar-besaran juga berdampak pada masuknya teknologi terbaru dalam kehidupan masyarakat. Masmundari menggambarkan perempuan turut ambil bagian dalam perubahan itu dengan menguasai teknologi.

\section{(3)Perempuan dalam Upacara Tradisional}

Menurut Mulder (Risa Permanadeli, 2015) pembagian peran simbolik antara laki-laki dan perempuan tetap terjaga dalam kehidupan sehari-hari: wong lanang nang ngarep, wong wedok nang mburi (laki-laki di depan, perempuan di belakang). Dikotomi keduanya tidak mengacu pada relasi kuasa satu sama lain. Sebaliknya, superioritas dalam dunia Jawa tidak bersifat hegemonik. Konsepsi paternalistik dalam keluarga menyatakan bahwa perempuan Jawa yang telah menjadi istri disebut sebagai konco wingking (teman di belakang). Gagasan tersebut cenderung mengalami peyorasi, bila tidak ditelaah secara mendalam. Menjadi konco wingking dalam konsep filosofi Jawa tidak selalu bermakna buruk dan rendah. Peran perempuan serupa dengan peran dalang dalam pagelaran wayang. Dalang melakukan tugasnya dibalik layar dan memainkan berbagai tokoh serta menentukan alur kisah yang diceritakan. Penonton pagelaran wayang tidak dapat melihat siapa yang menjadi dalang.

Masmundari banyak melukiskan adegan upacara tradisional dalam ragam hias damar kurung. Salah satu contohnya dapat dilihat pada Gambar 8. Karena dalam budaya Jawa identik dengan tatanan simbolik.
Upacara tradisional diadakan secara rutin sebagai tanda bergulirnya tahap kehidupan manusia. Upacara tradisional yang sering diadakan seperti upacara kelahiran anak, sunatan, perkawinan dan kematian.

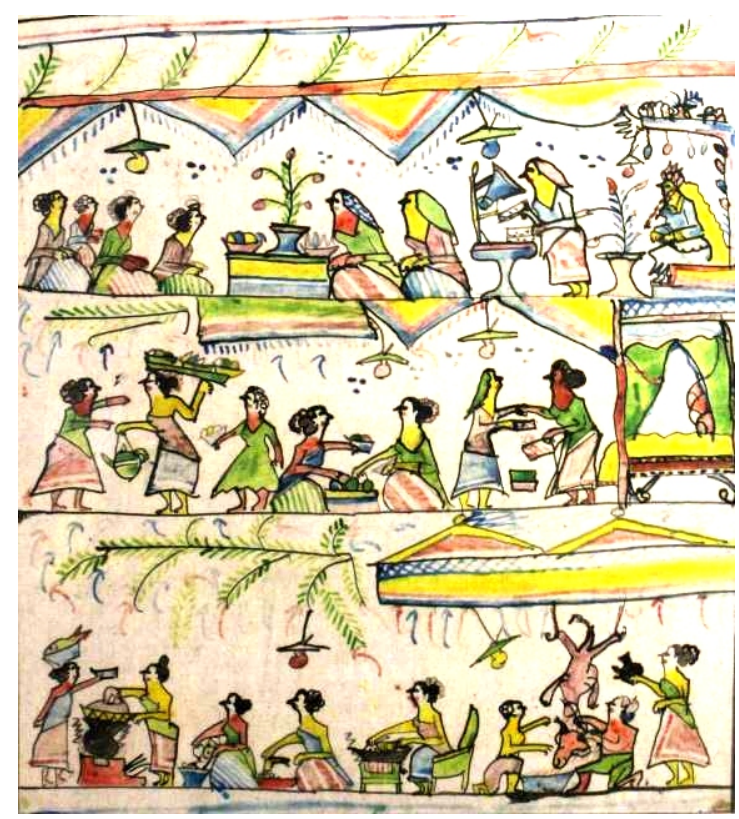

Gambar 8. Ragam Hias damar kurung dengan tema Perempuan dan Upacara Tradisional (Dokumentasi peneliti dari koleksi Oemar Zainuddin)

Meski dilakukan oleh perempuan, tahap belakang meliputi pekerjaan yang kasar dan berat, seperti mengolah daging kambing, memarut kelapa, dan mengaduk makan dalam kuali di atas tungku. Pada umumnya tahap belakang ini dibantu oleh kerabat perempuan (baik yang berhubungan keluarga maupun tidak) secara sukarela. Dalam budaya Jawa konsep perempuan saling bantu secara sukarela ini disebut dengan mbiyodo atau rewang. Tahap belakang ini telah diatur sebagai suatu rantai kerja yang dikerjakan oleh perempuan dari status sosial mana pun, usia berapa pun dan tingkat pendidikan apa pun. Berbeda dengan pekerjaan profesional, 
kegiatan ini tidak mempunyai job description yang jelas. Setiap perempuan yang terlibat harus peka mengetahui sejauh mana kemampuannya untuk dapat terlibat. Dalam proses inilah terjadi tukar menukar informasi, untuk merumuskan sekaligus membangun identitas sebagai perempuan Jawa.

Tahap depan (ritual doa) tidak akan terlaksana, jika tahap belakang tidak dilaksanakan oleh perempuan. Pria tidak akan bisa 'menghadap Tuhan' jika perempuan tidak mempersiapkan segala sesuatunya dengan baik. Hubungan vertikal manusia dan Tuhan dalam upacara tradisional adalah tanggung jawab penuh perempuan.

Motif Batik dari Ragam Hias damar kurung

Berdasarkan temuan tema ragam hias damar kurung sebelumnya, luaran penelitian ini diharapkan dapat menghasilkan desain motif dan pola batik kreasi baru berdasarkan kearifan lokal yang bersumber dari ide pengembangan ragam hias damar kurung. Serta menghasilkan produk kreatif (kriya dan fesyen) yang bermanfaat bagi pengembangan industri kreatif di Gresik. Selain itu, upaya pengembangan motif dan pola batik ini mengandung muatan konservasi bagi praktisi seni, desainer maupun pendidik untuk memanfaatkan potensi warisan budaya dalam rangka peningkatan ekonomi industri kreatif berbasis kearifan lokal. Tabel 1 menjelaskan desain motif dan pola batik berdasarkan temuan tema ragam hias damar kurung, perempuan dalam upacara tradisional, perempuan dan teknologi, serta perempuan dan kegiatan ekonomi.
Ragam hias batik terdiri atas hiasan-hiasan yang dikomposisikan sehingga membentuk suatu kesatuan rancangan yang berpola. Pola batik damar kurung ini menggunakan pola geometris, dimana terdapat bentukbentuk geometris (seperti persegi dan jajaran genjang) yang menjadi acuan pola. Motif batik damar kurung terinspirasi dari karakter Masmundari yang selalu melukiskan manusia tanpa perspektif, sederhana dan tampak samping. Motif disusun berulang menggunakan teknik tubrukan, parang dan mubeng. Baik motif maupun isen-isen disusun dalam irama pengulangan dan menyebar. Sehingga dapat diperoleh kesan keteraturan dan keselarasan. Batik damar kurung menggunakan warna-warna primer, seperti yang telah dilakukan Masmundari, yaitu terbatas pada warna merah, biru, dan kuning. Berdasarkan gayanya, batik damar kurung adalah batik kreasi baru, tanpa meninggalkan identitas/ciri khas dari bentuk yang diacu (Gambar 9).

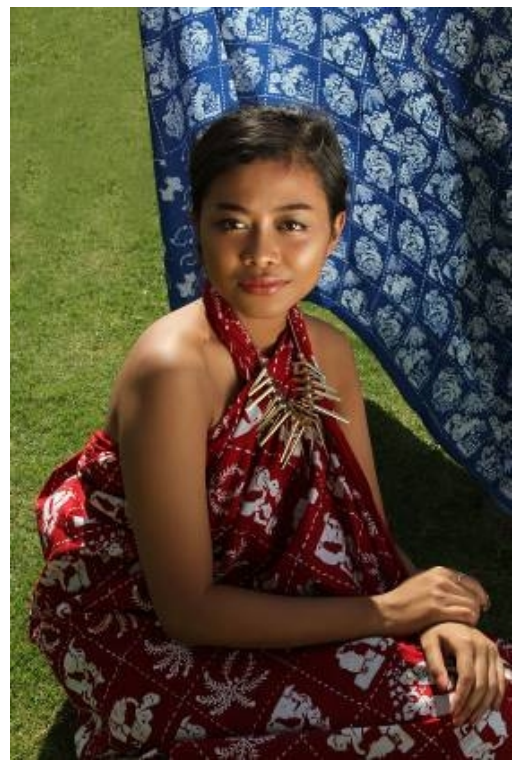

Gambar 9. Dokumentasi implementasi motif dan pola batik damar kurung 
Tabel 1. Tabel motif dan pola batik damar kurung

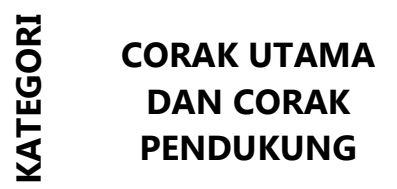

\section{CORAK LATAR BELAKANG}

\section{CORAK \\ PINGGIRAN}

RAGAM HIAS

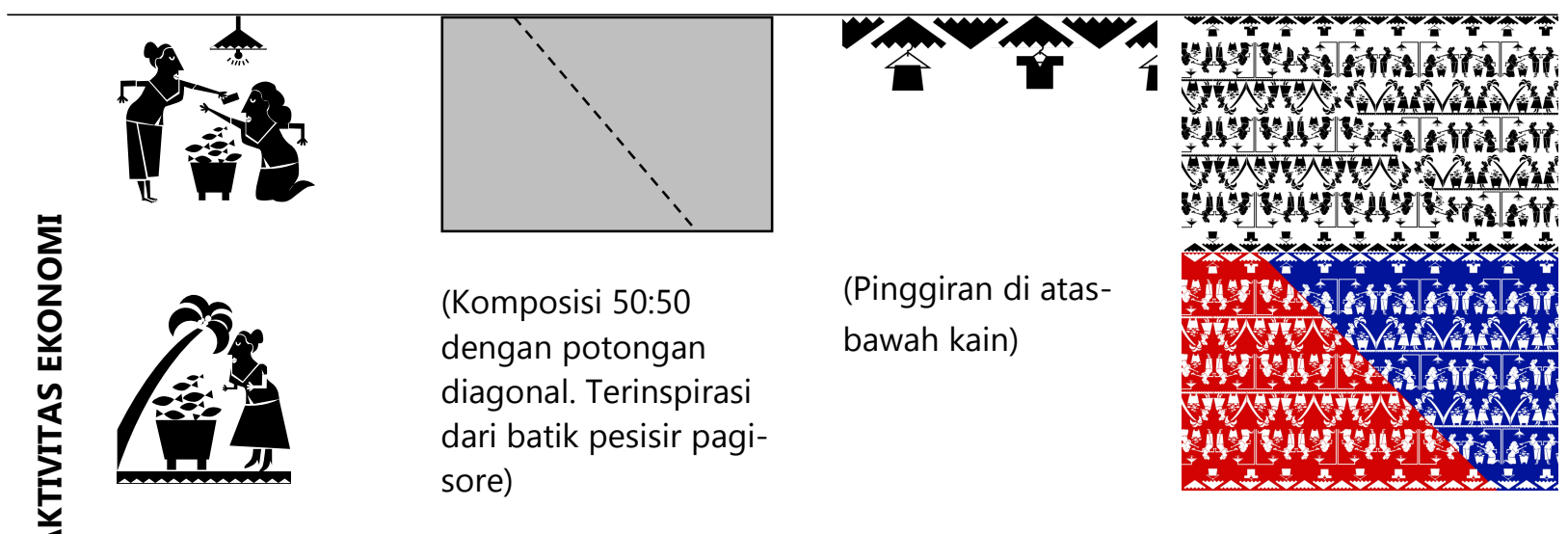

(corak

dikomposisikan

reflektif dan

diulang berjajar)

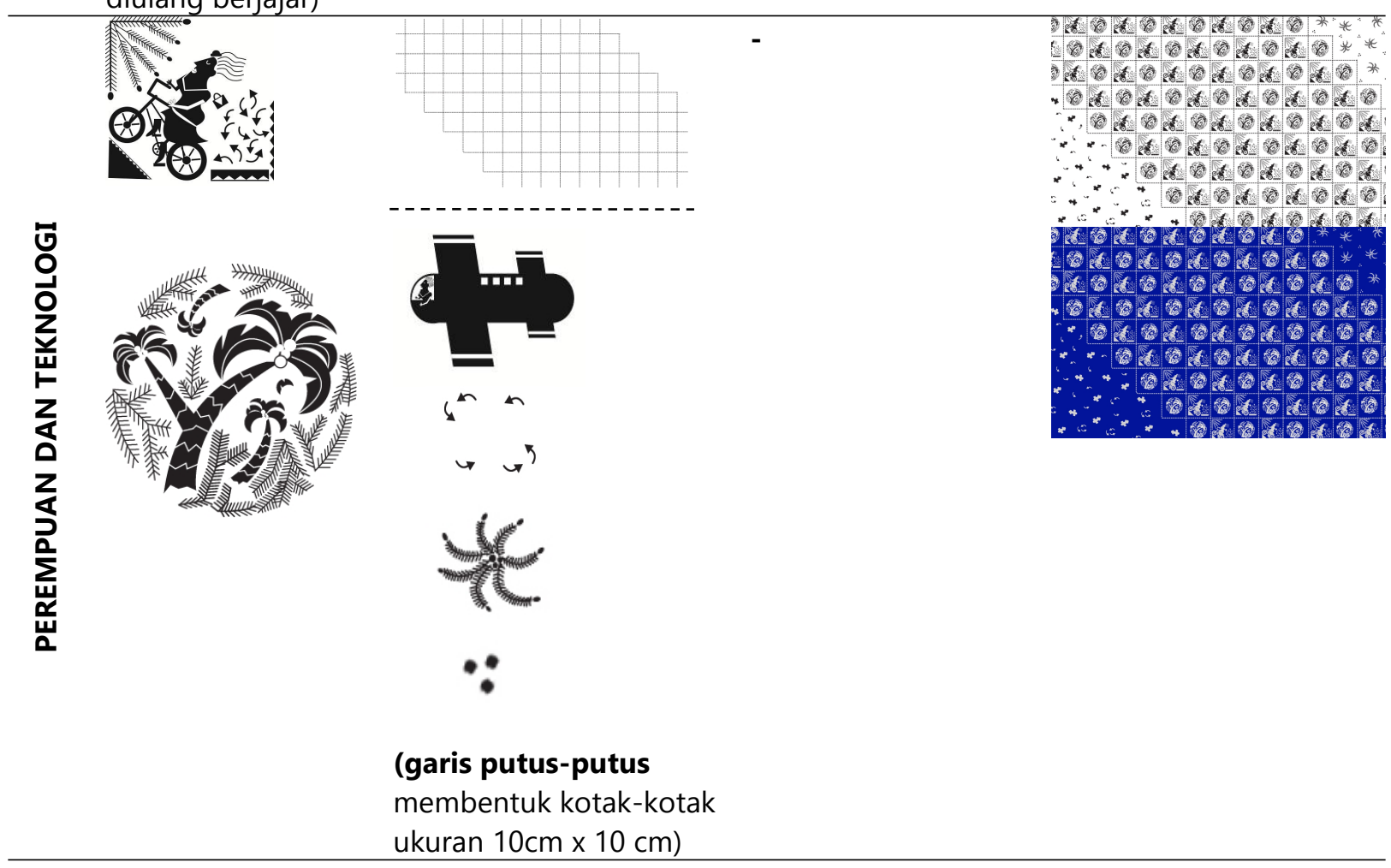




\section{용 CORAK UTAMA \\ DAN CORAK PENDUKUNG}

\section{CORAK LATAR \\ BELAKANG}

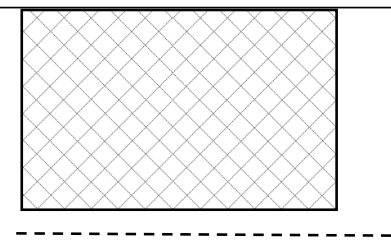

(garis putus-putus

membentuk kotak-kotak ukuran $10 \mathrm{~cm} \times 10 \mathrm{~cm}$ )
CORAK PINGGIRAN
RAGAM HIAS
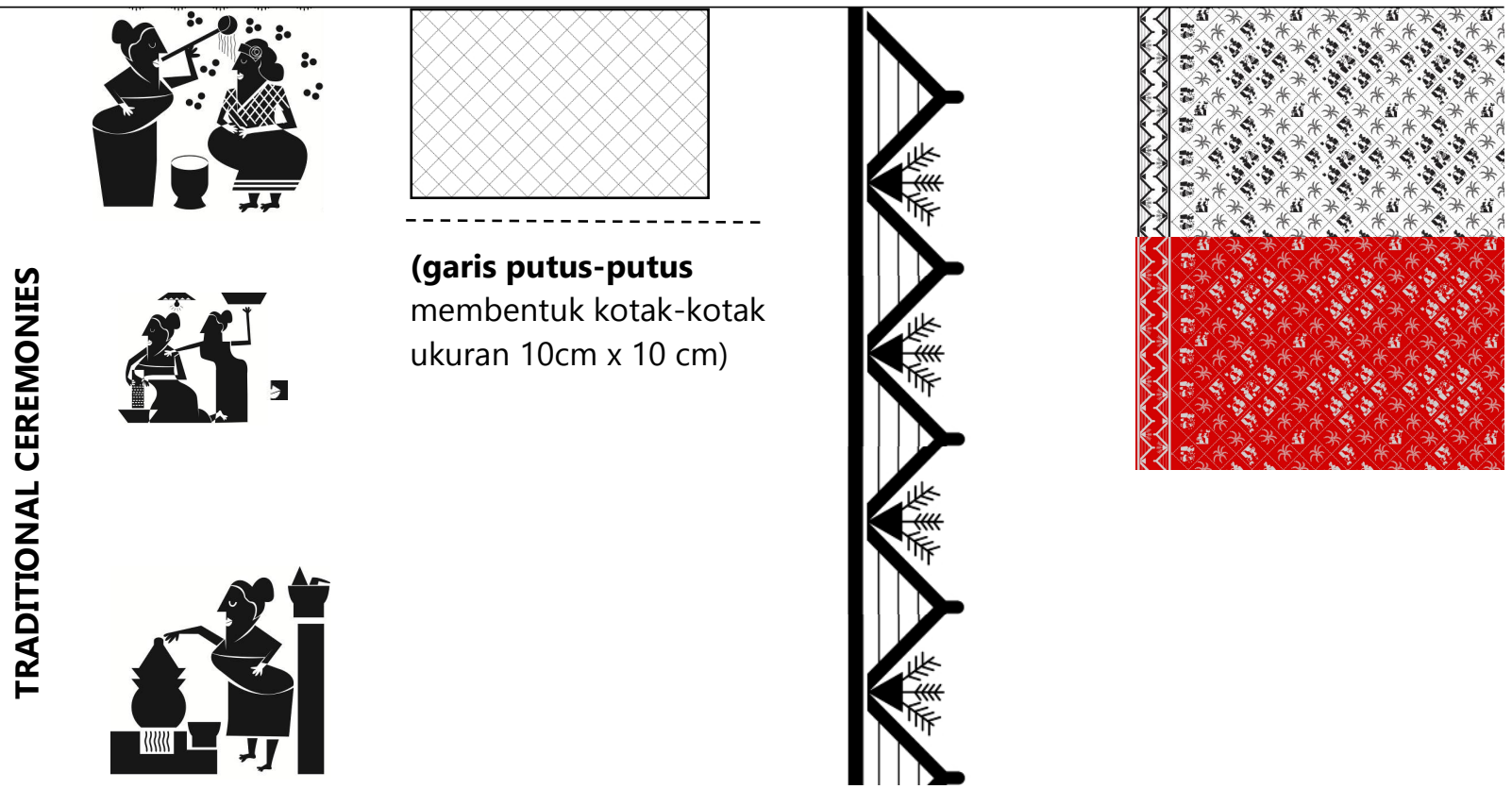

(Pinggiran di kanan-

kain saja)

\section{KESIMPULAN}

Perempuan dalam budaya Jawa berperan besar dalam dunia privat maupun publik dikarenakan kecerdasan emosional dan kekuatan feminitasnya. Menjadi perempuan Jawa memiliki pengertian yang sangat dalam dan luas, meliputi totalitas nilai-nilai dasar filosofi Jawa. Menjadi perempuan Jawa tidak bersifat material semata, melainkan gabungan aspek-aspek lainnya yang menitikberatkan pada aspek sosial-budaya. Paduan ini tidak terlepas dari orientasi budaya Jawa yang mengutamakan keselarasan lahir dan batin. Masmundari menyadari benar filosofi Jawa tersebut dan menjadikannya inspirasi dalam ragam hias damar kurung.
Desain motif dan pola batik damar kurung diharapkan dapat menjadi kelanjutan upaya Masmundari dalam menanamkan nilai-nilai luhur menjadi perempuan Jawa. Sehingga upaya pelestarian dan konservasi, damar kurung sebagai warisan nasional tak bendawi dapat terus dilakukan tanpa terbatas pada pelestarian artefak lentera semata. Desain motif dan pola batik damar kurung ini terbuka pada kemungkinan implementasi produk-produk kreatif lainnya.

\section{KONTRIBUSI PENULIS}

Aniendya Christianna merupakan kontributor utama pada tulisan ini, dan Luri Renaningtyas adalah kontributor anggota. 
ClKh Dinamika Kerajinan dan Batik: Majalah Ilmiah. Vol. 38 No. 1, Juni 2021, hal. 13 - 28

\section{UCAPAN TERIMA KASIH}

Penulis menyampaikan terima kasih sebesar-besarnya atas dukungan dari Program Studi Desain Komunikasi Visual Fakultas Seni dan Desain Universitas Kristen Petra, Lembaga Penelitian dan Pengabdian Masyarakat (LPPM) Universitas Kristen Petra, Novan Effendy: Direktur damar kurung Institute, Oemar Zainuddin, Penulis Buku 'Kota Gresik 1896-1916, Owner Batik Gajah Mungkur Gresik, Arti: Owner Griya Batik Gresik dan Owner Batik POER Collection, serta kepada Owner Café Omah Damar Gresik.

\section{DAFTAR PUSTAKA}

Agustina, T. K. (2017). Pengaruh Sanggar Batik Rumpaka Mulya Wringinganom terhadap Perkembangan Batik Loh Bandeng Gresik Tahun 2005-2012. AVATARA, e-Journal Pendidikan Sejarah, Volume 5,. https://jurnalmahasiswa.unesa.ac.id/index. php/avatara/article/view/19382/17700

Benedetti, J. M. (2008). Folk Art Terminology Revisited: Why It (Still) Matters. Radical Cataloging: Essays at the Front. McFarland. p. 113. ISBN 978-1-4766-0512-8.

BPS Gresik Regency. (2013). Gresik. 1-10. http://bappeda.jatimprov.go.id/bappeda/w p-content/uploads/potensi-kab-kota2013/kab-gresik-2013.pdf

Christianna, A. (2018a). The Role of damar kurung Lantern as A Time Signal of Gresik Society. Jurnal Sosioteknologi, 17(1), 65-73. https://doi.org/10.5614/sostek.itbj.2018.17. 1.7

Christianna, A. (2018b). The Representation of Javanese Women in damar kurung Painting - Gresik. Mudra Jurnal Seni Budaya, 33(3), 295-301.

https://doi.org/10.31091/mudra.v33i3.376

Christianna, A. (2020). Preservation of damar kurung through Jewelry Design. Productum: Jurnal Desain Produk (Pengetahuan Dan Perancangan Produk), $3(7)$, 247-254. https://doi.org/10.24821/productum.v3i7.3 343
Christianna, A., Wibowo, M., \& Nilasari, P. F. (2020). Empowering Women through Batik Training in Dolly's Ex-Localization Area. https://doi.org/10.2991/icracos-19.2020.17

Geertz, C. (1990). The Javanese Family: a Study of Kinship and Socialization. New York: The Free Press of Glencoe. Inc.

Hakim, L. M. (2018). Batik sebagai Warisan Budaya Bangsa dan Nation Brand Indonesia. Jounal of Internasional Studies, 1(1), 60-89.

Indrakusuma, D. (2003). 90 Tahun Mengabdi Untuk Seni Tradisi Masmundari Mutiara dari Tanah Pesisir. Gresik: Pustaka Pesisir.

Ismoerdjahwati, I. (2014). Budaya Nusantara melalui damar kurung: Analisis Bahasa Rupa. Jurnal Budaya Nusantara, 1(1), 84-91. https://doi.org/10.36456/b.nusantara.vol1. no1.a387

Loh Bandeng Salah Satu Ikon Batik Gresik. (2012). September 25, 2012. https://gresik.co/loh-bandeng-salah-satuikon-batik-gresik/

Mashuri, M. (2017). Kesejarahan Desa-Desa Pesisir dalam Serat Sindujoyo. Manuskripta, $7(2)$, 89-117. https://doi.org/10.33656/manuskripta.v7i2. 96

Permanadeli, Risa. (2015). Dadi Wong Wadon:Representasi Sosial Perempuan Jawa di Era Modern. Yogyakarta: Pustaka Ifada.

Pramitasari, N. L. G. F. (2017). Eksistensi Wanita dalam Manawa Dharmasastra (Perspektif Teologi Gender). Jurnal Penelitian Agama Hindu, 1(1), 24-31.

Pramudita, C. A. (2016). Konsep Diri Perempuan Jawa: Pembentukan dan Orientasi. Skripsi. Fakultas Psikologi. Universitas Sanata Dharma.

Pratiwinindya, R. A. (2017). Simbol Gendhèng wayangan pada Atap Rumah Tradisional Kudus dalam Perspektif Kosmologi JawaKudus. Catharsis, 6(1), 19-27. https://doi.org/10.15294/catharsis.v6i1.170 28

Rasjoyo. (2008). Mengenal Batik Tradisional. Azka Press.

Rohman, B. N. (2018). Interelasi Masyarakat dan Identitas Sosial (Studi Kasus: Identitas Sosial Model Perempuan). Fakultas Ilmu Sosial dan Ilmu Politik Universitas Islam 
clKh Dinamika Kerajinan dan Batik: Majalah Ilmiah. Vol. 38 No. 1, Juni 2021, hal. 13 - 28

Negeri Syarif Hidayatullah Jakarta. http://repository.uinjkt.ac.id/dspace/bitstre am/123456789/42837/1/BEBY NURDIANA ROHMAN-FISIP.pdf

Sachari, A. (2010). Budaya Visual Indonesia. Jakarta: Penerbit Erlangga.

Sastriyani, Hariti, R.A.S, dan Kayam, U. (1997). Genduk Duku karya Y.B. Mangunwijaya: Tinjauan sosiologi sastra dan pemaknaan semiotik. Tesis. Fakultas Sastra. Universitas Gadjah Mada.

Soedarsono SP. (1998). Seni Lukis Batik Indonesia Batik Klasik Sampai Kontemporer. Yogyakarta: IKIP Negeri Yogyakarta.

Syabrina, R. A. N. (2014). Perancangan Buku Visual damar kurung dan Masmundari Sebagai Maestro Kesenian Gresik. Jurnal Sains dan Seni POMITS, 2(1), 1-6.

Tjahjani, I. (2013). Terampil Membatik untuk Siswa. Jakarta: Penerbit Erlangga.

Trismaya, N. (2018). Kebaya dan Perempuan: Sebuah Narasi tentang Identitas. JSRW (Jurnal Senirupa Warna), 6(2). https://doi.org/10.36806/JSRW.V6I2.41

Udin, M. (2015). Nilai-Nilai Perdamaian dalam Teks Wacan Sindujoyo Babad Kroman Gresik. SMART, 1(1). https://doi.org/10.18784/smart.v1i1.225

Utama, M. W. P. (2015). Estetika Seni Lukis Karya Masmundari. Skripsi. Fakultas Seni Rupa dan Desain. Institut Seni Indonesia Surakarta.

Utama, M. W. P. (2017). Model Pelukisan Ilustrasi Di Dalam Serat Babad Sindujoyo. Dimensi DKV, 2(1), 1-16.

Uyun, Q. (2017). Tradisi Lelang Bandeng sebagai Identitas Sosial Kabupaten Gresik. Skripsi. Fakultas Ilmu Sosial dan Politik. Universitas Muhammadiyah Malang.

Wahyu, R.S. (2013). damar kurung (Makna Lukisan damar kurung sebagai Kesenian Masyarakat Gresik). AntroUnairDotNet, 2(1), 114-123.

Wulandari, A. (2011). Batik Nusantara: Makna Filosofis, Cara Pembuatan, dan Industri Batik. Yogyakarta: Penerbit Andi. 
IKh Dinamika Kerajinan dan Batik: Majalah Ilmiah. Vol. 38 No. 1, Juni 2021, hal. 13 - 28 